\title{
Clinical characteristics of Korean asthmatic patients who showed negative skin prick tests, but positive specific lgE tests for fungus
}

Byoung Whui Choi

From 3rd WAO International Scientific Conference (WISC) 2014

Rio de Janeiro, Brazil. 6-9 December 2014

\section{Background}

Sensitivity to allergens has been recognized as a risk factor for the development of asthma. There was few study about clinical significances of positive specific IgE Tests for fungus in patients with negative skin prick tests for fungus.

\section{Objective}

We aimed to investigate clinical characteristics of asthmatics who showed negative skin prick tests, but positive specific IgE tests for fungus. The clinical difference between serum fungus-specific IgE-positive and -negative asthmatics who showed negative skin prick tests was also examined.

\section{Method}

A total of 38 patients who showed negative skin prick tests after undergoing 50 common allergens including D. farinae, D. pteronyssiuns and 5 fungi (Penicillium notatum, Cladosporium, Aspergillus fumigatus, and Alternaria,Fusarium spp.) with positive methacholine provocation test provocation test and chronic lower respiratory symptoms were included in this study.

\section{Results}

In 16 patients (42.1\%) with negative serum specific IgE tests for both fungi and HDM, total IgE $(76.1+64.7$ $\mathrm{KU} / \mathrm{L}$ ) was significantly lower than in $14(36.8 \%)$ patients with positive serum specific IgE tests for fungi $(730.1+$ $948.41 \mathrm{KU} / \mathrm{L}$ ) and in 16 patients $(42.1 \%)$. with positive serum specific IgE tests for HDM $(783.5+854.1 \mathrm{KU} / \mathrm{L})$, respectively. In patients with negative serum specific IgE tests for both fungi and HDM, FEV1 \% predicted
$(95.9+19.2 \%)$ was significantly higher than in patients with positive serum specific IgE tests for fungi $(75.5+$ $24.2 \%$ )and in patients with positive serum specific IgE tests for HDM $(76.7+27.3 \%)$, respectively. In patients with negative serum specific IgE tests for both fungi and HDM, PC20 $(2.61+1.32 \mathrm{mg} / \mathrm{ml})$ was significantly higher than in patients with positive serum specific IgE tests for fungi $(2.23+2.05 \mathrm{mg} / \mathrm{ml})$ and in patients with positive serum specific IgE tests for HDM $(1.34+$ $1.12 \mathrm{mg} / \mathrm{ml}$ ), respectively.

\section{Conclusion}

In asthmatic patients who showed negative skin prick tests, but high serum IgE, serum specific igE test for both fungi and HDM might be needed for detection of HDM.

Published: 8 April 2015

doi:10.1186/1939-4551-8-S1-A260

Cite this article as: Choi: Clinical characteristics of Korean asthmatic patients who showed negative skin prick tests, but positive specific $\lg \mathrm{E}$ tests for fungus. World Allergy Organization Journal 2015 8(Suppl 1):A260.

Chung-Ang University Hospital, South Korea 